\title{
The influence of substituents position on products of dinitrotoluene isomers initial thermal decomposition
}

\author{
T. Gołofit ${ }^{1}$ (D) T. Zielenkiewicz ${ }^{2}$
}

Received: 19 July 2016/ Accepted: 26 October 2016/Published online: 10 November 2016

(c) The Author(s) 2016. This article is published with open access at Springerlink.com

\begin{abstract}
Thermal decomposition of dinitrotoluene (DNT) isomers and formed products were studied. Initial stage of thermal decomposition was the field of interests because decomposition of even a few percent of a substance may cause hazard. The generation of impurities at the initial stage of decomposition was examined on the basis of the decrease of the original substance melting enthalpy and the increase of impurities fraction determined with cryometric method. MALDI TOF was used as the independent method of formed compounds molar masses determination. Samples of DNT isomers at raised temperature (up till $480 \mathrm{~K}$ ) undergo aggregation leading to macromolecular substances. Regardless the substituents position, the initial phase of decomposition leads to same intermediate products. Mass spectra of DNT isomers thermally conditioned contain strong signals $\mathrm{m} / \mathrm{z}$, among others, 688, 1063, 1137, 1211. Thermogravimetric analysis revealed that observed difficulties with studying the decomposition initial stage are related to high vapor pressure below decomposition temperature, what especially concerns $2,6-\mathrm{DNT}$ isomer.
\end{abstract}

Keywords Dinitrotoluene - DSC - MALDI TOF · Nitro-compounds aggregation - Thermal decomposition

T. Gołofit

tomgol@ch.pw.edu.pl

1 Faculty of Chemistry, Warsaw University of Technology, Noakowskiego 3, 00-664 Warsaw, Poland

2 Faculty of Wood Technology, Warsaw University of Life Sciences, Nowoursynowska 166, 02-787 Warsaw, Poland

\section{Introduction}

Industrial manufacturing of dinitro-derivatives of toluene (DNT) is related to their wide application not only as high energetic mixtures, but also as other semi-products in the chemical industry, e.g., polymerization reactions $[1,2]$. The knowledge about parameters determining thermal stability of DNT allows safety maintenance during the performance of technological operations with their participation. Uncontrolled decomposition of nitro-compounds may lead to the accident [1]. That is why studies of hazard related to high energetic compounds thermal decomposition are performed [3-8]. Thermal explosion is the phenomenon which causes the strongest hazard during technological processes, storage and exploitation of nitro-compounds. Thermal explosion occurs as the result of cumulation of heat released in the decomposition reaction [3], and it may take place even with low conversion degree [4]. That is why detailed studies of the initial stage of thermal decomposition are significant. The fact, that it occurs below the temperature when exothermic effect of decomposition is visible, is its special feature. From this reason, one of the methods of the initial stage of decomposition process examination is liquidcrystal equilibrium studying, and especially determination of impurities content influence on this equilibrium temperature shift [7-9]. The equilibrium is very sensitive to impurities content and allows studying the initial stage of decomposition. The aggregation of partially degraded 2,3DNT molecules to macromolecules with molecular mass even above $1000 \mathrm{Da}$ is also suggested [7]. The thermal stability of these compounds is significantly different in comparison with original substance.

Thermal decomposition of dinitrotoluenes was often examined with DSC analysis [7, 10-14], adiabatic reactionary calorimeter (ARC) was also used [10], and 
decomposition products were determined with the application of mass spectrometer [11]. The first stage of nitrocompounds decomposition differs depending on the substituents position in the aromatic ring. Nitro-group without substituents in ortho position may undergo the homolytic separation from the ring and following regrouping to nitrite group [12]. Two nitro-groups in ortho position may react with each other forming benzofurazan and benzofuroxane $[8,15]$. Nitro-group in the neighborhood of methyl group leads to anthranil $[16,17]$. It is accepted that in case of ortho-nitrotoluenes, homolytic cleavage of $\mathrm{C}-\mathrm{H}$ bond in the methyl group is the first stage of decomposition and in the second step hydrogen attaches oxygen atom in nitrogroup $[10,18]$. Then number of subsequent reaction take place which forms gaseous products. Case's studies [19] indicate that at the temperature below $573 \mathrm{~K}$, stable solid phase product of dinitrotoluenes decomposition is formed which immediately decomposes to gaseous products above mentioned temperature. Maksimov [20] studied the thermal decomposition of 2,4-DNT, 2,6-DNT and 3,5-DNT analyzing gaseous products. He calculated decomposition rate constants at $500 \mathrm{~K}$, the highest for 2,4-DNT and the lowest for 3,5-DNT.

The relevant literature does not contain any systematic studies about DNT isomers decomposition products and influence of substituents on the thermal stability and decomposition products. No complex studies containing particular analysis of all DNT isomers with the same analytical technique were performed. It is unfavorable because changing of the method may influence the thermal decomposition process [21]. That is why thermal stability parameters and decomposition products cannot be compared on the basis of the existing literature. The aim of this paper is to perform complex examination of the influence of nitro-groups position on all of the DNT isomers decomposition products and the influence of conditioning parameters on the decomposition process.

\section{Experimental}

\section{Materials}

Examined substances were synthesized in Military University of Technology in Warsaw. Table 1 presents cryometrically determined purity and physicochemical parameters of studied substances. Values from the literature were also included for comparison. Purity was also determined with gas chromatography; its value was $99.9 \%$ for all substances.

Distinctions in determined samples purity are related to the measuring methods specifics. Content of compounds soluble in liquid phase are measured in cryometric method, while in GC method-substances volatile in increased temperature. It may lead to the conclusion that compounds with high molecular mass are the impurities. Differences between determined parameters (melting enthalpy and temperature) and literature values may be related to different purity of analyzed compounds.

\section{Methods used}

Micro-calorimeter UNIPAN DSC 605 was used for studies. It was calibrated with indium, cadmium, naphthalene, tin and benzoic acid. Purity of metals used for calibration was above $99.999 \%$, and purity of organic compounds-above 99.95. Sample of analyzed substance was closed in aluminum pan under reduced pressure of ca. $1.3 \mathrm{kPa}$.

Measurements were taken with $2 \mathrm{~K} \mathrm{~min}^{-1}$ rate. Measurements of the melting process were terminated after the formation of base line. Non-isothermal conditioning was lead to the assumed temperature or visible exothermic effect of decomposition, when the increase of calorimetric signal indicated for high thermal power, experimentally determined, which may lead to the device destruction. Isothermal conditioning was conducted at the temperature in the middle of melting point and decomposition temperature range.

Liquid-crystal equilibrium was applied to analyze decomposition products. This equilibrium is very sensitive for impurities content in liquid phase. Small amount of impurities causes significant decrease of substance melting temperature. Following assumptions were introduced: Components are totally miscible in the liquid phase and totally immiscible in the solid phase; melting enthalpy of components in considered temperature range is approximately independent on the temperature; the solution is diluted enough to be described with ideal solution model.

Molar concentration of impurities-purity of analyzed compound may be calculated from cryometric equation $[8,9,24,25]$ :

$$
T_{\mathrm{m}}=T_{\mathrm{m}}^{0}-\frac{R \times\left(T_{\mathrm{m}}^{0}\right)^{2}}{\Delta H_{\mathrm{m}}} \times x \times \frac{1}{F}
$$

where $F$-sample melting degree, $x$-real molar fraction of impurities, $T_{\mathrm{m}}^{0}$-melting temperature of perfectly pure substance, $T_{\mathrm{m}}$-sample melting temperature, $\Delta H_{\mathrm{m}}$-melting enthalpy. On the basis of impurities molar fraction, purity of the sample may be determined from following equation:

$P=(1-x) \times 100 \%$

Sample becomes contaminated with decomposition products during thermal analysis performance. Leading the measurement to arbitrarily chosen final temperature $T_{\mathrm{f}}$, the 
Table 1 Melting temperature $\left(T_{\mathrm{m}}\right)$, melting enthalpy $\left(\Delta H_{\mathrm{m}}\right)$ and purity $(P)$ of studied dinitrotoluenes

\begin{tabular}{|c|c|c|c|c|c|}
\hline Isomer & $T_{\mathrm{m}} / \mathrm{K}$ & $\Delta H_{\mathrm{m}} / \mathrm{kJ} \mathrm{mol}^{-1}$ & $T_{\mathrm{m}}(\mathrm{lit}) / \mathrm{K}$ & $\Delta H_{\mathrm{m}}(\mathrm{lit}) / \mathrm{kJ} \mathrm{mol}^{-1}$ & $P / \mathrm{mol} \%$ \\
\hline 2,3-DNT & 332.7 & 16.13 & $329.7[22]$ & $17.5[22]$ & 99.9 \\
\hline 2,4-DNT & 343.7 & 21.49 & $340.7[22]$ & $22.2[22]$ & 99.2 \\
\hline 2,5-DNT & 324.5 & 15.67 & $323.6[23]$ & & 99.4 \\
\hline 2,6-DNT & 338.3 & 18.02 & $327.4[22]$ & $23.8[22]$ & 99.9 \\
\hline 3,4-DNT & 332.4 & 18.52 & 329.4 [22] & 18.8 [22] & 99.8 \\
\hline 3,5-DNT & 366.0 & 19.79 & $366.1[22]$ & & 99.9 \\
\hline
\end{tabular}

increase of impurities takes place $(\Delta x)$, which is equal to the difference between molar fraction of impurities in the sample taken for analysis $\left(x^{0}\right)$ and in the sample after decomposition $\left(x_{\mathrm{f}}\right)$. The increase of impurities fraction equals the real molar fraction of impurities $(x)$ related to the thermal decomposition.

$\Delta x=x^{0}-x_{\mathrm{f}}=\sum_{\mathrm{i}} x_{\mathrm{i}}$

where $x_{\mathrm{i}}$-molar fraction of " $i$ " decomposition product. Introducing the assumption that one molecule of the liquid phase impurity is formed during the decomposition of one molecule of the examined substance, and other vapor impurities are in the gaseous phase; the value of real molar fraction of impurities $(\Delta x)$ should be equal to the initial substance conversion degree $\left(\alpha_{\mathrm{f}}\right)$. If the value of $\Delta x$ is higher than $\alpha_{\mathrm{f}}$ parameter, then it means that on average, more than one molecule of the liquid phase impurities is formed during decomposition of one molecule of initial substance. However, when parameter $\Delta x$ is lower than $\alpha_{\mathrm{f}}$ parameter, molecules of decomposition products in liquid phase aggregate to each other forming molecules with molecular mass higher than initial compound. The size of these aggregates could be defined with the so-called mean aggregation number $(\lambda)$ [26-28], which may be calculated on the basis of following equation:

$\Delta x=\frac{\alpha_{\mathrm{f}}}{\lambda-\lambda \times \alpha_{\mathrm{f}}+\alpha_{\mathrm{f}}}$

MALDI TOF analysis of decomposition products molecular mass was performed in the Centre of Macromolecular Research in Lodz, using Kratos Kompact Maldi 4 apparatus with nitrogen laser with the wavelength of $22 \mathrm{~nm}$, impulse of $3 \mathrm{~ns}$, positive polarization, accelerating voltage of $20 \mathrm{kV}, 200$ impulses for each spectrum. Decomposition products were dissolved in acetone to perform analysis.

Thermogravimetric analysis was performed using TA Instruments SDT Q600 device. Measurements were taken for samples with mass of $5.2 \pm 0.1 \mathrm{mg}$, in aluminum pans covered or closed with the cover with $75 \mu \mathrm{m}$ hole. Nitrogen flow of $100 \mathrm{~mL} \mathrm{~min}{ }^{-1}$ and temperature increase rate $\beta=5.0 \mathrm{~K} \mathrm{~min}^{-1}$ were applied.

\section{Results and discussion}

Examination of strong exothermic decomposition of DNT isomers was problematic because of high vapor pressure and gaseous products of decomposition. High pressure inside hermetic measuring pan made of aluminum foil caused deformation and unsealing at high temperatures. Timely termination of the measurement was the only way to analyze decomposition products. Examining baseline of thermo-analytical curve before low temperature decomposition peak, specific deviation from linear character may be observed. It is related to exothermic decomposition of the compound. Figure 1 presents exemplary curve of melting and decomposition of $14 \mathrm{mg}$ 2,4-DNT sample (two runs on the same sample).

The first run shows sample melting process and hightemperature deviation of DSC curve indicating for the beginning of compound exothermic decomposition. Melting process in the second run begins at the lower temperature, and its thermal effect is lower, what is caused by initial substance decomposition and impurities production in the first run. Formation of low molecular compounds as the result of high-temperature conditioning was initially expected. In that case, impurities increase denoted in mol\% should be higher than the decrease of the melting enthalpy.

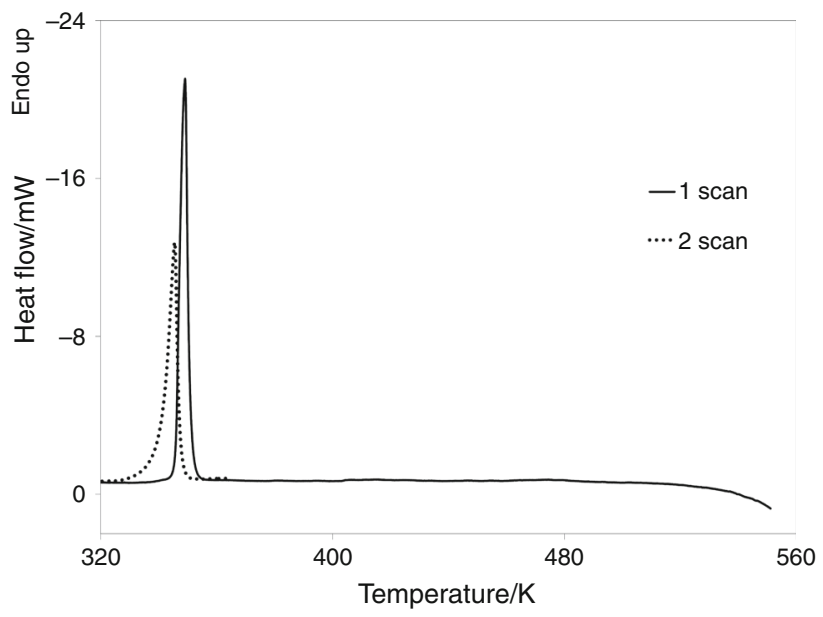

Fig. 1 DSC curves of melting and partial decomposition of $14 \mathrm{mg}$ 2,4-DNT sample 
The opposite effect was denoted in all cases-impurities increase was lower than enthalpy decrease. Mean aggregation number was calculated, and results are presented in Table 2. As it was mentioned above, decomposition often leads to the measuring pan unsealing because of high vapors pressure.

Comparing thermo-analytical curves of melting processes of samples conditioned at temperatures much higher than melting point, thermal decomposition of DNT may be observed. Mean aggregation number $\lambda$ higher than 1 indicates for the isolation of impurities from the liquid phase or the impurities reaction leading to compounds with higher molecular mass. In order to confirm the possibility of high molecular mass compounds formation, spectra of samples with the application of MALDI TOF device were performed. To verify MALDI TOF method usefulness for decomposition products examination, samples before and after conditioning were measured. Spectra obtained for 2,4DNT are presented in Fig. 2.

Mass spectrum of the standard sample contains low signals with high $\mathrm{m} / \mathrm{z}$ values (above 500). This material has been stored for dozens of years at the ambient temperature. Aggregation reaction could proceed in these conditions, leading to macromolecular products formation. Mass spectrum of thermally conditioned 2,4-DNT sample contains strong signals with values of 551, 688, 1062, 1137, 1211. These results indicate that molecular mass of initial decomposition products exceeds several dinitrotoluene mass. Oligomers with similar molecular masses were observed in the initial and in thermally conditioned sample. The intensities of peaks in the initial sample are obviously significantly lower in relation to conditioned samples. Similar decomposition products testify that the mechanism

Table 2 Final temperature $\left(T_{\mathrm{f}}\right)$, the real mole fraction $\Delta \bar{x}$ and the mean association number $(\lambda)$ of decomposition products of dinitrotoluenes

\begin{tabular}{lllll}
\hline Isomer & $T_{\mathrm{f}} / \mathrm{K}$ & $\Delta x \times 100$ & $\lambda$ & Comments \\
\hline 2,3-DNT & 562 & 3.76 & 7.7 & Unsealing \\
& 552 & 3.90 & 3.9 & \\
$2,4-\mathrm{DNT}$ & 548 & 3.54 & 5.6 & Unsealing \\
& 530 & 1.53 & 6.1 & \\
$2,5-\mathrm{DNT}$ & 562 & - & - & Unsealing \\
& 553 & 2.21 & 4.6 & \\
$3,4-\mathrm{DNT}$ & 566 & 5.71 & 13.3 & \\
& 552 & - & - & Unsealing \\
$3,5-\mathrm{DNT}$ & 575 & 10.0 & 0.9 & Unsealing \\
& 577 & 0.45 & 29.3 & \\
2,6-DNT & 555 & 1.08 & 8.3 & Unsealing \\
& 556 & 2.30 & 25.8 & Unsealing \\
& 458 & -0.05 & - & Unsealing \\
\hline
\end{tabular}

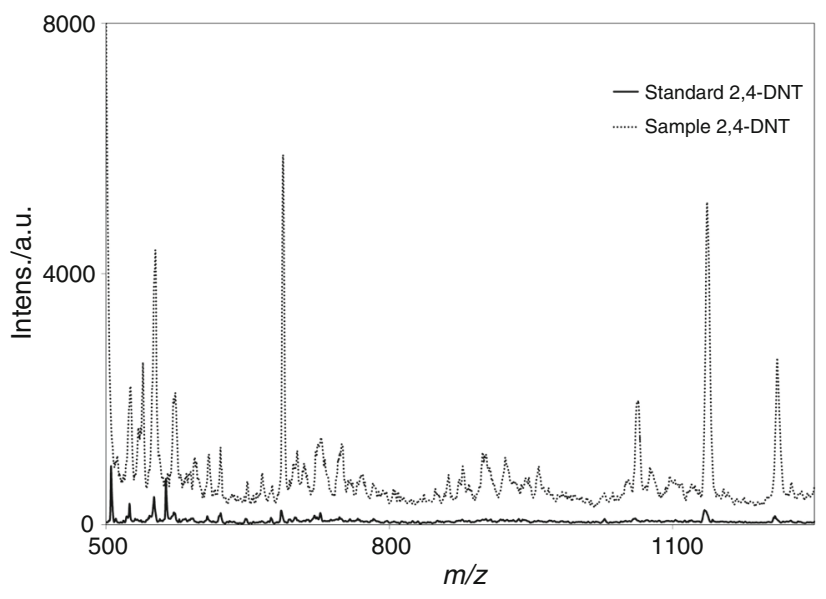

Fig. 2 MALDI TOF mass spectra of 2,4-DNT sample before and after thermal conditioning

of DNT decomposition at increased and ambient temperature is the same. The same test was carried out for the other DNT isomers. The obtained spectra are shown in Fig. 3.

Mass spectra for all isomers before and after conditioning were compared. Oligomers with the same molecular masses were observed in both initial and conditioned samples. Intensities of peaks for conditioned samples are higher again. That is why it can be concluded that for all isomers, mechanism of decomposition at increased and ambient temperature is the same. Repeatability of these results despite differences in nitro-groups location is very interesting. It may mean that regardless the location of substituents, the initial stage of decomposition runs similarly, but for sure leads to identical by-products. Only for 2,6-DNT sample, the number of repeated peaks with high intensities is not visible. It is related to low temperature of partial decomposition measurement termination. Measurement of 2,6-DNT sample was terminated at only $459 \mathrm{~K}$.

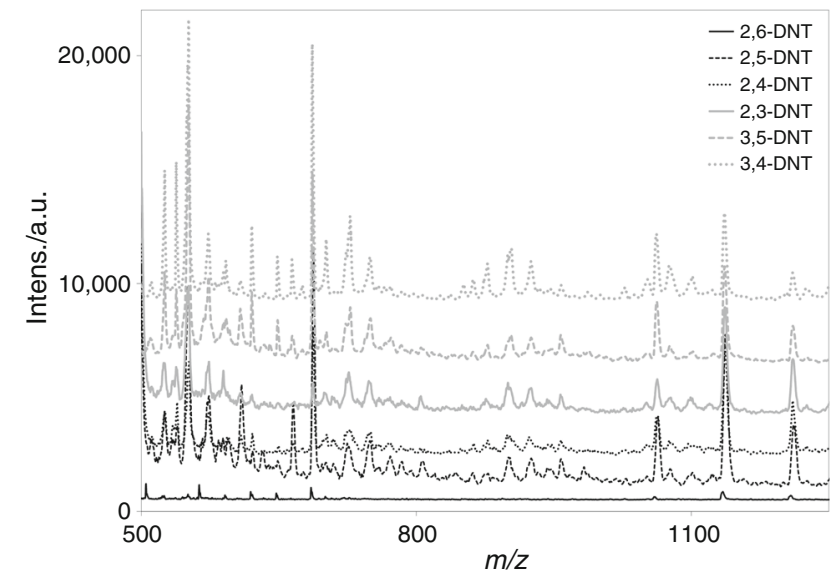

Fig. 3 MALDI TOF mass spectra of DNT isomers after nonisothermal conditioning 
The increase of sample purity with $0.05 \%$ was observed after measurement performed this way. Measurement that leads to higher temperatures caused measuring pans unsealing and examined substance pouring out.

Process of DNT isomers decomposition was analyzed also in isothermal conditions. Cycle of measurements of melting and isothermal conditioning at temperatures below $500 \mathrm{~K}$ was performed for each DNT isomer excluding 2,6DNT (because of problems mentioned above). Exemplary series of 2,5-DNT melting is shown in Fig. 4.

As the result of consecutive processes of isothermal conditioning, melting peaks become wider, lower, and shift in the direction of lower temperatures, what is related to impurities production. Samples after conditioning were submitted for MALDI TOF analysis. Table 3 contains the comparison of MALDI TOF results for all of examined substances for the most intense peaks.

Similar decomposition products (the same molecular masses) were obtained for all DNT isomers samples conditioned isothermally, alike as earlier for non-isothermal conditioning. It indicates again that regardless substituents position, the initial stage of decomposition follows the same way. From the other hand, the participation of particular oligomers in the spectrum is dependent on substituent position in the molecule. Peak with the highest intensity was obtained for M/z equaled 688 (2,3-DNT) and 1137 (the rest of isomers).

Problems with partial decomposition measurements performance in case of 2,6-DNT isomer could be related to high pressure of compound vapor below the decomposition temperature. To investigate this issue, total decomposition process in samples of mass above $10 \mathrm{mg}$ was studied with thermogravimetry. The first series of measurements was conducted in pans covered (but not closed) by the lid with

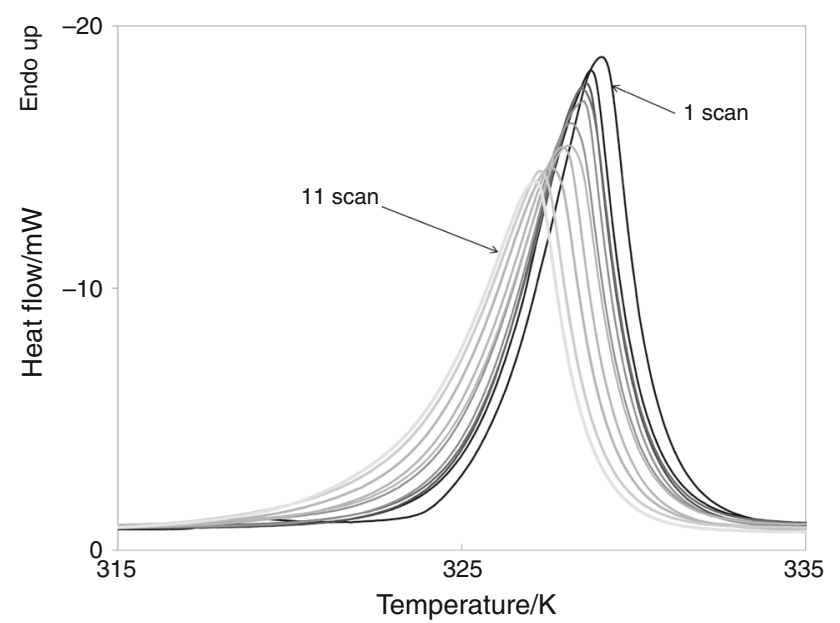

Fig. 4 Series of DSC curves of 2,5-DNT melting process preceded by isothermal conditioning
Table 3 MALDI TOF analysis results obtained for DNT isomers samples conditioned isothermally with DSC calorimeter

\begin{tabular}{llllll}
\hline$m / z$ & \multicolumn{5}{l}{ Isomer } \\
\cline { 2 - 6 } & \multicolumn{5}{l}{ Peak height/\% } \\
\cline { 2 - 6 } & 2,3 -DNT & $2,4-\mathrm{DNT}$ & 2,5 -DNT & $3,4-\mathrm{DNT}$ & 3,5 -DNT \\
\hline 666 & 17 & 14 & 40 & - & 19 \\
688 & 37 & 100 & 100 & 100 & 100 \\
699 & 22 & 20 & 14 & - & 20 \\
703 & 31 & - & 15 & 25 & 21 \\
724 & 20 & 20 & 23 & - & 24 \\
728 & 53 & 23 & 22 & 35 & 32 \\
750 & 27 & 22 & 24 & 20 & 27 \\
1063 & 37 & 34 & 35 & 28 & 36 \\
1137 & 100 & 86 & 66 & 36 & 53 \\
1211 & 49 & 44 & 31 & 14 & 24 \\
1286 & 18 & 18 & 14 & - & 12 \\
\hline
\end{tabular}

the hole from the safety reasons. Obtained TG and DSC curves are presented in Fig. 5.

The mass loss of DNT isomers occurred in the temperature range of $400-550 \mathrm{~K}$. It was related to the sample evaporation for all isomers. The mass loss process for 2,6DNT sample started and ended at the lowest temperature. Rapid exothermic process of decomposition, which could destroy measuring nest, was not observed. That is why consecutive measuring series was conducted with the pan close tight with the lid with the hole. Results are presented in Fig. 6.

Closing of pans caused the increase of mass loss beginning of about $70 \mathrm{~K}$. Process of 2,6-DNT mass loss began and ended at the lowest temperature again. It was related to the sample evaporation $\left(T_{\text {onset }}=563 \mathrm{~K}\right.$, $T_{\max }=567 \mathrm{~K}$ ). Also for 2,5-DNT and 3,5-DNT, the mass loss was connected to sample evaporation (correspondingly: $T_{\text {onset }}=571 \mathrm{~K}, \quad T_{\max }=579 \mathrm{~K} ; \quad T_{\text {onset }}=586 \mathrm{~K}$, $T_{\max }=592 \mathrm{~K}$ ). Insignificant exothermic process related to decomposition is visible at the end of evaporation process. Below $1 \%$ of solid residue remained after the decomposition of 2,5 2,6 and 3,5-DNT at the temperature of $650 \mathrm{~K}$. Process of 2,3-DNT mass loss was exothermic with overlaying strong endothermic effect $\left(T_{\text {onset }}=587 \mathrm{~K}\right.$, $T_{\max }=591 \mathrm{~K}$ ). Its course is irregular, what is related to blocking of the lid hole with decomposition products. Solid residue after 2,3-DNT decomposition (at $650 \mathrm{~K}$ ) was $4 \%$. Process of 2,4 and 3,4-DNT mass loss was exothermic (correspondingly: $T_{\text {onset }}=578 \mathrm{~K}, T_{\max }=582 \mathrm{~K} ; T_{\text {on- }}$ set $=587 \mathrm{~K}, T_{\max }=592 \mathrm{~K}$ ). Solid residue value after decomposition at $650 \mathrm{~K}$ was the highest and equaled correspondingly 12 and $13 \%$. 
(a)

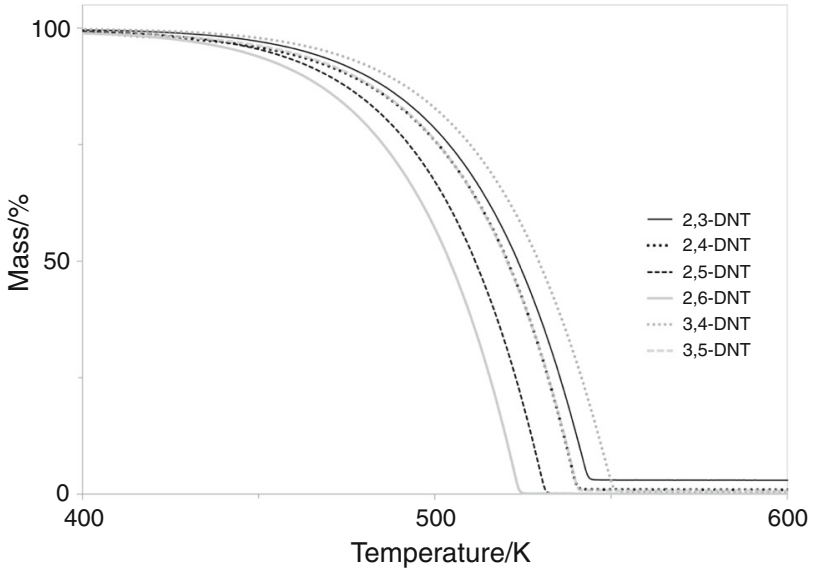

(b)

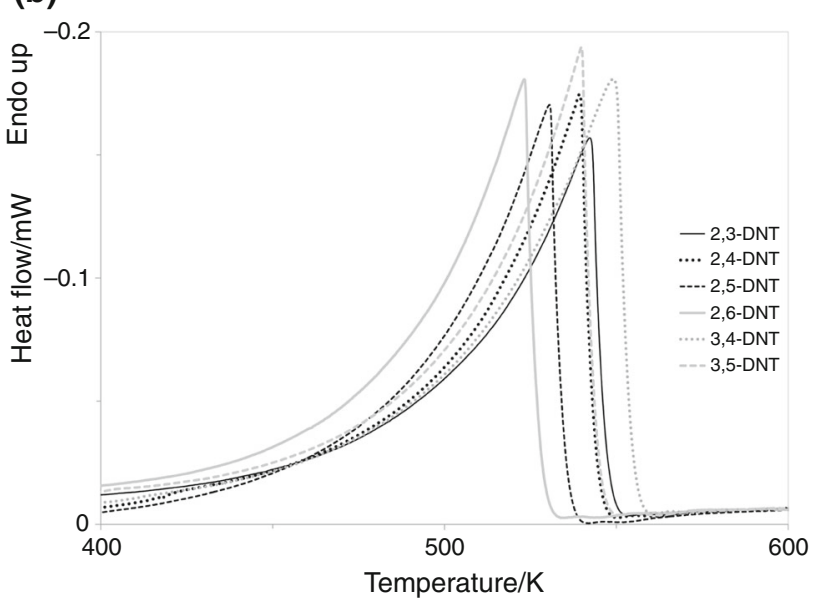

Fig. 5 TG (a) and DSC (b) curves of mass loss and related thermal effects of DNT isomers samples heated with the temperature increase rate of $5 \mathrm{~K} \mathrm{~min}^{-1}$ in pans covered with the lid with $75 \mu \mathrm{m}$ hole

Obtained results confirmed that problems with the analysis of 2,6-DNT decomposition initial stage are regarded to high vapor pressure below the decomposition temperature. 2,4-DNT was the compound decomposing at the lowest temperature. These results are compatible with literature data [20].

\section{Conclusions}

DNT isomers are polar molecules, and their dipole moment may be responsible for their tendency to aggregation. High polarity leads to the molecules approach and intermolecular reactions. Increased temperature, up till $480 \mathrm{~K}$, does not cause advanced decomposition, but contrary, aggregation is the dominant reaction at these temperatures. MALDI TOF analysis confirms this thesis, as well as the decrease of melting enthalpy higher than cryometric estimated increase of impurities content. Besides the aggregation causes the (a)

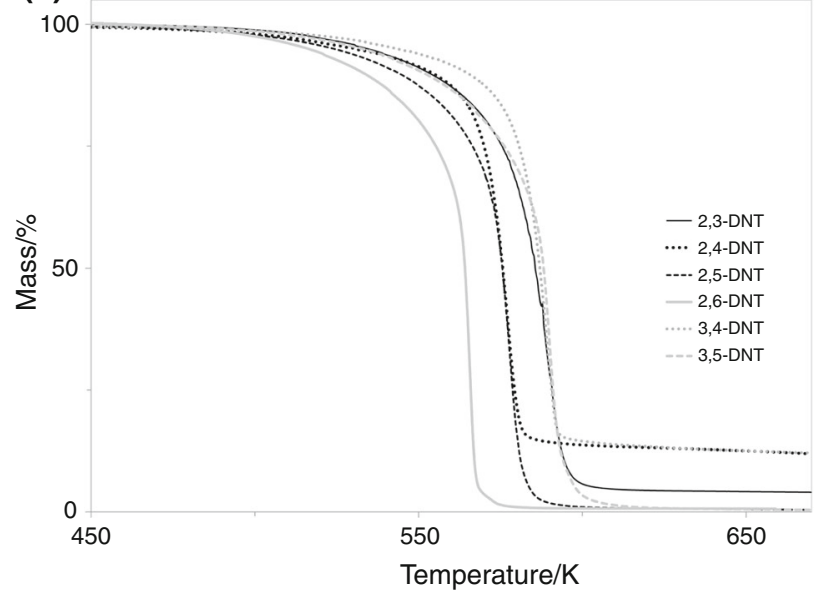

(b)

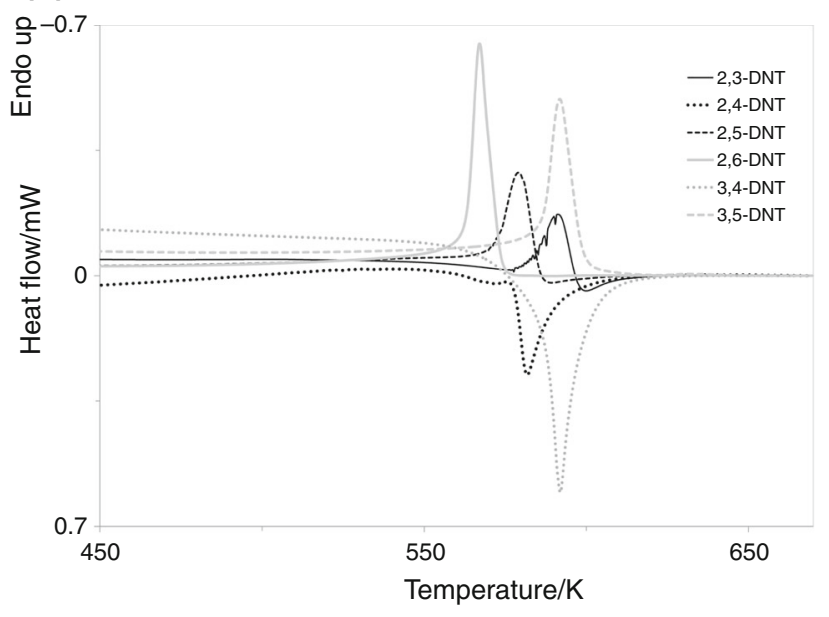

Fig. 6 TG (a) and DSC (b) curves of mass loss and related thermal effects of DNT isomers samples heated with the temperature increase rate of $5 \mathrm{~K} \mathrm{~min}^{-1}$ in pans closed tight with the lid with $75 \mu \mathrm{m}$ hole

decrease of molar impurities fraction, it may be also decreased with the lack of solubility of impurities in the liquid phase of DNT. It also testifies for the aggregation because macromolecules hardly dissolve in liquid organic substances. Aggregation causes the increase of content of compounds which are thermally more stable than initial substance, and improvement of the sample stability. The analysis of the initial stage of DNT isomers decomposition revealed that both at the ambient and increased temperature, similar macromolecular aggregation products are formed and it does not depend on substituents location. Mass spectra of thermally conditioned DNT samples contain strong signals $\mathrm{m} / \mathrm{z}$ with values of (among others) 688, 1063, 1137 and 1211.

Thermogravimetric studies confirmed that problems with the examination of the initial stage of 2,6-DNT decomposition are related to high vapor pressure below the decomposition temperature. 2,4-DNT is the isomer decomposing at the lowest temperature. 
Open Access This article is distributed under the terms of the Creative Commons Attribution 4.0 International License (http://crea tivecommons.org/licenses/by/4.0/), which permits unrestricted use, distribution, and reproduction in any medium, provided you give appropriate credit to the original author(s) and the source, provide a link to the Creative Commons license, and indicate if changes were made.

\section{References}

1. Zhang GZ. Bin cause of " 5.11 " explosion in Cangzhou Dahua TDI branch factory. Xiaofang Kexue Yu Jishu. 2008;27(8):615-7.

2. Bock M, Baumann R, Franzke A, Stroefer E, Theis G. Method for the combined production of diisocyanates and/or polyisocyanates and glycols. WO Patent 2011051314 A1; DE; 2011.

3. Han Z, Sachdeva S, Papadaki MI, Mannan S. Effects of inhibitor and promoter mixtures on ammonium nitrate fertilizer explosion hazards. Thermochim Acta. 2016;624:69-75. doi:10.1016/j.tca. 2015.12.005.

4. Lu GB, Zhang CX, Chen WH, Chen LP, Zhou YS. Thermal hazards and kinetic analysis of salicyl hydroxamic acid under isothermal and adiabatic conditions. Thermochim Acta. 2016;623:43-9. doi:10.1016/j.tca.2015.11.005.

5. Semenov NN. Chemical kinetics and chain reactions. London: Oxford University Press; 1935.

6. Abramov VG, Vaganova NI. Effect of a side reaction with small heat liberation on the critical thermal-explosion condition of the main selfcatalyzed reaction. Fiz Goreniya Vzryva. 1978;14(5):135-41. doi:10.1007/BF00789730.

7. Gołofit T, Zielenkiewicz T. Liquid-crystal equilibrium application for 2,3-dinitrotoluene initial thermal decomposition analysis. J Therm Anal Calorim. 2016; doi:10.1007/s10973-016-5261-9.

8. Ksiazczak A, Ksiazczak T, Zielenkiewicz T. Influence of purity on the thermal stability of solid organic compounds. J Therm Anal Calorim. 2004;77:233-42. doi:10.1023/B:JTAN.0000033208. 42367.97.

9. Ksiazczak A, Ksiazczak T. Kinetic data of low-temperature thermal decomposition of N,2,4,6-tetranitro-N-methylaniline. Thermochim Acta. 1996;284(2):299-308. doi:10.1016/00406031(95)02505-7.

10. Duh Y, Lee C, Hsu C, Hwang D, Kao C. Chemical incompatibility of nitrocompounds. J Hazard Mater. 1997;53:183-94. doi:10.1016/S0304-3894(96)01829-8.

11. Ando T, Fujimoto Y, Morisaki S. Analysis of differential scanning calorimetric data for reactive chemicals. J Hazard Mater. 1991;28(3):251-80. doi:10.1016/0304-3894(91)87079-H.

12. Minier LM, Brower KR, Oxley JC. The role of intermolecular reactions in thermolysis of aromatic nitro compounds in supercritical aromatic solvents. J Org Chem. 1991;56:3306-14.
13. Fields EK, Meyerson S. Arylation by aromatic nitro compounds at high temperatures. II. Nitrobenzene alone and with benzene and benzene-d6. J Am Chem Soc. 1967;89:3224-8.

14. Maksimov YY, Sorochkin SB, Titov SV. Kinetics and mechanism of the thermal decomposition of mononitrobenzene in vapors. $\mathrm{Tr}$ Mosk Khim Technol Inst im. DI Mendeleeva. 1980;112:26-31.

15. Bliss DE, Christian SL, Wilson WS. Impact sensitivity of polynitroaromatics. J Energ Mater. 1991;9:319-45. doi:10.1080/ 07370659108018631.

16. Tsang W, Robaugh D, Mallard WG. Single-pulse shock-tube studies on $\mathrm{C}-\mathrm{NO}_{2}$ bond cleavage during the decomposition of some nitro aromatic compounds. J Phys Chem. 1986;90(22):5968-73. doi:10.1021/j100280a101.

17. He YZ, Cui JP, Mallard WG, Tsang W. Homogeneous gas-phase formation and destruction of anthranil from $o$-nitrotoluene decomposition. J Am Chem Soc. 1988;110(12):3754-9. doi:10. 1021/ja00220a006.

18. Shackelford SA. Mechanistic investigations of condensed phase energetic material decomposition processes using the kinetic deuterium isotope effect. In: Bulusu SN, editor. Chemistry and physics of energetic materials: proceedings of the NATO Advanced Study Institute. Dordrecht: Kluwer; 1990. p. 413-32.

19. Case JL, Carr RVC, Simpson MS. Modeling To gain insight into thermal decomposition of dinitrotoluene. ACS Symp Ser. 1996;623:174-86.

20. Maksimov YY. Effect of the vapor-liquid state of aggregation on the thermal decomposition rate of aromatic polynitro compounds. Zh Fiz Khim. 1971;45(4):793-6.

21. Gańczyk K, Zygmunt A, Gołofit T. Thermal properties of TEX decomposition or sublimation. $\mathrm{J}$ Therm Anal Calorim. 2016;125:967-75. doi:10.1007/s10973-016-5476-9.

22. Borchardt HJ, Daniels F. Application of differential thermal analysis to the study of reaction kinetics. J Am Chem Soc. 1957;79:41-6.

23. Beckmann JW, Wilkes JS, McGuire RR. 2,4,6-Trinitrotoluene thermal decomposition: kinetic parameters determined by the isothermal differential scanning calorimetry technique. Thermochim Acta. 1977;19:111-8. doi:10.1016/0040-6031(77)80053-1.

24. Widmann G, Scherrer O. A new program for DSC purity analysis. J Therm Anal Calorim. 1991;37(8):1957-64.

25. Książczak A. Applications of differential thermal analysis to studies on impurities in substances of 99.9 to 99.9999 percent purity. Pol J Chem. 1981;55(5):1127-33.

26. Kempter H, Mecke R, Teil B. Spectroscopic determination of association equilibrium. Z Phys Chem. 1940;46:229-41.

27. Książczak A, Anderko A. Prediction of solid-liquid equilibria on the basis of pure compound properties. Fluid Phase Equilib. 1987;35:127-51.

28. Książczak A. Effect of auto-association on solid-liquid equilibrium. Fluid Phase Equilib. 1986;28:39-56. 